\title{
PRE-COLLEGE BIOMEDICAL ENGINEERING PROGRAM FOR GIRLS
}

\author{
Nicole B. Koppe1 ${ }^{1}$, Rosa M. Cano ${ }^{2}$, Suzanne B. Heyman ${ }^{2}$, and Tara L. Alvarez ${ }^{3}$ \\ ${ }^{1}$ Department of Information \& Decision Sciences, Montclair Sate University, Upper Montclair, NJ \\ ${ }^{2}$ Center for Pre-college Programs, New Jersey Institute of Technology, Newark, NJ \\ ${ }^{3}$ Department of Biomedical Engineering, New Jersey Institute of Technology, Newark, NJ
}

\begin{abstract}
When choosing a career in scientific fields, girls tend to gravitate towards professions that help humanity; thus, the fields of health and medicine are widely chosen by women. To attract young women to engineering careers, girls need to be shown that engineering is used to improve the quality of people's lives. Biomedical engineering applies engineering principles to further medical research via basic research to understand how the human body operates or through collaboration with clinicians to facilitate the diagnosis and/ or cure of diseases. NJIT Center for Pre-college Programs offer the Women In Engineering \& Technology (WEIT)FEMME program to encourage pre-college female students to pursue careers in science, technology, engineering, and mathematics (STEM) fields. In 2001, Biomedical Engineering FEMME became the newest addition to the WIET Initiative specifically geared towards girls completing the eighth grade. The academic curriculum integrates engineering principles with biomedical science, and introduces girls to the role of engineers as "problem-solvers and helpers".

Index Terms - biomedical engineering, pre-college program, women in engineering.
\end{abstract}

\section{AN ENGINEERING PROGRAM FOR GIRLS}

Since 1981, New Jersey Institute of Technology's (NJIT) FEMME, Women in Engineering and Technology (WIET) initiative has addressed the under-representation of women in science, technology, engineering, and mathematics (STEM) fields in effort to increase the number of women entering and completing scientific careers.

Today, the FEMME programs offer 120 fourth through ninth grade girls an intensive four-week summer academic program.

The FEMME program utilizes discussions, experiments, projects, and field trips to help students master problem solving skills in STEM and learn about computers, engineering and communication principles. These activities utilize "gender friendly" instruction and teamwork. Mentoring sessions introduce students to female scientists and engineers. Each grade level has an engineering thematic unit that links all subjects and activities.

In 2001, Biomedical Engineering became the newest thematic unit in our WIET initiative. This paper will discuss our rationale for initiating a biomedical engineering (BME) theme and the academic curriculum of the program.

\section{Why GiRls St ILl Do Not WANT To Be ENGINEERs?}

Over the last two decades much work has been done to address the needs of women and girls in STEM areas and to develop interventions that encourage girls to pursue and succeed in STEM careers. Both girls' and boys' participation in high school mathematics and science courses has increased. There are now minimal differences in girls' and boys' "average" science and math scores on the National Assessment of Educational Progress tests.

The gender gap in science and mathematics achievement has narrowed. Today, girls take upper level math and science courses in the same numbers as boys. In fact, $43 \%$ of students enrolled in physics are girls. Also, an equal number of boys and girls are enrolled in advanced placement biology and calculus courses.[1][2] Programs and initiatives that encourage hands-on research have yielded better education for girls in STEM areas.

While young women have the academic ability and background they are not pursuing engineering careers. Despite mentorship programs, scholarships, and curricular changes, the percentage of female engineers has not grown.

Although the majority of undergraduate students in the U.S. are women, the proportion of women enrolled in engineering programs is approximately 20\%.[3]

For years, educators assumed that women's lack of interest in the field was due to the programs being male-dominated and a heavy mathematics and science curriculum. According to William A. Wulf, president of the National Academy of Engineering, positive changes in other traditionally male-dominated fields such as law and medicine, which today are close to gender parity, refute that theory. Even though medicine is an area heavily associated with advanced math and science.

Women are more inclined to study subjects they find socially relevant, having a positive influence in people's lives. Women avoid engineering because of negative perceptions deeply ingrained throughout their social development and the reputation of engineering as an esoteric "stealth profession". [4]

One way to attract young women to the fields of technology and engineering is to introduce them to engineers as "problem solvers" who utilize engineering principles to improve people's lives. One discipline that fulfills this criterion is BME.

\section{GROWTH OF BIOMEDICAL ENGINEERING}

BME is the application of engineering principles and new technologies to define and solve problems in the fields of medicine and biology. It is a discipline that advances knowledge in engineering, biology and medicine, and improves human health through cross-disciplinary activities that integrate the engineering sciences with the biomedical sciences and clinical practice.

Although BME has been around for nearly 50 years, there is a renewed interest and rapid growth in the number of graduates in this discipline. Universities across the country are establishing BME departments. There are 90 institutions of higher education in the U.S. and Canada that offer programs in BME, many of which formed within the last 3 to 4 years. Fifty additional institutions are developing similar programs. [5]

The growth of university programs is due to the large demand for BME professionals. According to the U.S. Department of Labor's Bureau, by 2010, BME jobs will 
increase by $31.4 \%$ while overall job growth will average $15.2 \% .[6]$

The large number of jobs in this sector of engineering is attributed to the increasing demand for improved medical devices and systems, coupled with an aging U.S. population. Another catalyst is the demand for cost-effective and efficient procedures and equipment.

BME is an attractive engineering option for women because of its direct impact on people's lives. By nature, women are caregivers; therefore BME is a tangible avenue to positively impact humanity. Since BME is a relatively new area of engineering, it does not have the "stealth profession" reputation and no stereotypical "glass ceiling", providing women with more advancement opportunities.

\section{FEMME PROGRAM IN BME}

In 2001, Biomedical Engineering-FEMME8 became the newest addition to the WIET umbrella at NJIT. The program is designed for girls completing the $8^{\text {th }}$ grade, and its thematic focus was chosen because of the natural interest of girl to the fields of health and medicine. Academic curricula introduced female students to the application of engineering principles and to methods of solving clinical problems in the fields of health and medicine.

The goal of the curriculum is to introduce participants to the diverse areas and aspects of BME. FEMME8 participants' typical day included instruction in biomedical engineering, communications, mathematics, and computers. The BME curriculum consisted of clinical practice combined with the medical and engineering sciences. The course was divided into several modules including: biomechanics, bioinstrumentation, computational biology and tissue engineering, biomaterials, and rehabilitation and clinical engineering.

- Biomechanics - application of classical and fluid mechanics to biological motion. The FEMME8 module included instruction on limb replacements, footwear design, prosthetic design, and orthopedics. The girls conducted several activities where they investigated how the absence of a finger or arm would affect their ability to perform simple tasks, such as tying a shoe.

- Bioinstrumentation-application of electronics and measurement techniques to develop devices used in the diagnosis and treatment of disease. FEMME8 built pacemaker batteries from lemons and tomatoes to illustrate environmentally-safe conductive materials

- Computational Biology \& Tissue Engineeringstudy of internal processes of the body and the development of cellular matrix and stem cell research to create natural tissue. FEMME8 students were involved in discussions and debates on these topics and participated in an experiment where they tried to create identical masks to demonstrate cloning and then modify the "cloned" mask.

- Biomaterials - study of materials used for human implants, including both living tissue and artificial substances. FEMME8 investigated the compatibility of different materials with the human body. Students had the opportunity to study and handle actual biomaterials used for hip replacements, spinal discs, and artificial knee joints.
- Rehabilitation \& Clinical Engineering - study of concepts in biomechanics and other areas to develop devices that enhance the quality of life for individuals with physical and cogitative impairments. FEMME8 designed wheelchairs to enable people with spinal cord impairments, such as paraplegics and quadriplegics, or missing limbs, to participate in sports, such as racing or basketball.

Field trips, which focused on how biomedical engineering is applied to the "real-world", enhanced the academic curriculum. Select field trips included the following: The Cardiac Classroom at Liberty Science Center in Jersey City, NJ where visitors watch cardiac surgery at Morristown Memorial Hospital via a live audio and video connection and speak directly to operating room staff while the operation is in progress; Kessler Institute, a hospital, rehabilitation, and research center, in West Orange, NJ, with a biomedical research lab; the genomics lab at the Public Health Research Institute, in Newark, NJ where research is conducted on cancer cells by way of genetic coding; University Hospital in Newark, NJ which has an autopsy lab, a gross anatomy lab, and a trauma center; the Neuroscience Lab at Rutgers University where extensive modeling of the nervous system is being done; and the Biomedical Vision Engineering Lab at the NJIT BME department which is devoted to understanding how the brain visually processes data as well as developing instruments to aid patient with visual pathologies.

\section{CONCLUSION}

At the completion of the summer component, many Biomedical Engineering-FEMME8 students expressed interest in pursuing careers in the biomedical field. The combination of hands-on activities and field trips facilitated a positive environment that fostered learning and allowed the students to get a "real-life" experience in what biomedical engineering entailed.

Although initiatives to educate both girls and boys about STEM careers are necessary, it is crucial that these initiatives include systemic support to nurture, protect, and encourage girls to pursue careers in traditionally maledominated fields. It is imperative that girls recognize that engineers have a positive impact on the world. Biomedical engineering can serve as the vehicle to bring change to the mainstream perception of engineering and its numerous possibilities.

The goal of increasing the number of women pursuing and successfully completing careers in STEM is part of NJIT's mission. A first step toward this mission is the Biomedical Engineering-FEMME8 program.

\section{REFERENCES:}

[1] National Center for Educational Statistics, U.S. Department of Education, http://nces.ed.gov/.

[2] Campbell, P.B., and Clewell, B.C., "Science, math, and girls", Education Week, Vol. 19, No. 2, September 15, 1999, pp. 50+.

[3] Congressional Commission on the Advancement of Women and Minorities in Science, Engineering and Technology Development report, "Land of plenty," September 2000.

[4] Farrell, EF, "Engineering a warmer welcome for female students", The Chronicle of Higher Education, February 22, 2002.

[5] Smith, F, "New Measures Bioengineering and the Whitaker Foundation", HMS Beagle: The BioMedNet Magazine, Issue 105, 2001.

[6] U.S. Department of Labor, Bureau of Labor Statistics, http://www.bls.gov/home.htm. 